\title{
Analysis of the Influencing Factors of Cultural Differences on Second Language Acquisition
}

\author{
Yaping Tang
}

\begin{abstract}
This paper analyzes the influence of cultural differences on second language acquisition from the aspects of lexis, language, non-language communication, thinking, psychology, and linguistic background. The conclusion is that culture is a process of accumulation. The original social and life experience, cultural knowledge and thinking ability will become boosters for learners to know and understand the culture of target language. Therefore, cultural differences have a direct impact on second language acquisition.
\end{abstract}

Index Terms-Cultural differences, influencing factors, second language acquisition.

\section{INTRODUCTION}

In Genesis, there is a famous myth of the Tower of Babel, which says that man made a concerted effort to build a tower to the heaven, but this great ambition exasperated God. Lest it should endanger his authority, so God descended to the world "where their accents were disturbed and their language impassable to one another"[1]; when men spoke in different tongues, and quarreled with each other, the great work of the tower was lost. This myth has profound implications, and points out the importance of language in the formation of human life and culture. So what's the function of language? The two main functions of languages have been summarized in the previous studies: interactive function and transactional function. Interactive function refers to human beings need to use languages as medium to interact and communicate with others. Using language to express happiness, sadness or whatever emotion is the category of interactive function. The transactional function refers to that people use language to transfer knowledge and skills, which promotes the spread and continuation of civilization [2].

Culture covers a wide range. It not only refers to the values, thinking patterns and emotions formed by a nation in its long-term life, but also refers to the lifestyle and communication styles of a nation, such as common living habits, customs, speech and behavior. Language, on the other hand, is a system of symbols to express ideas. It is both a carrier of culture and a part of culture [3]. Culture is an abstract concept with a large extension and a deep connotation. In view of this, the definition of "culture" is still a controversial issue .The division of its extension is usually based on its object, so culture is divided into material culture, social culture (collective communication culture or social communication culture), and spiritual culture (spiritual

Manuscript received August 9, 2019; revised November 5, 2019.

Tang Yaping is with Yunnan University for Nationalities, China ( e-mail: 493623316@qq.com). civilization). Spiritual culture is based on and carried by language. Therefore, it can be said that language is the basic unit of spiritual culture, and it belongs to and serves for spiritual culture. Moreover it can be pointed out that the expansion of the relationship between language and culture is the relationship between spiritual culture and social culture. Language and culture are always bidirectional permeable. Language reflects the objective reality of culture by its symbols, and specific culture is reflected in specific social life style, social customs, behavioral norms and other aspects. Therefore, people in a specific cultural environment will be influenced by the specific social and historical development, and their metaphorical cognitive mode will also be influenced by the culture, which will be revealed and affect (dominate or control) the language acquisition. In consequence, cultural background or cultural differences play an important role in the process of language acquisition [4].

\section{THEORIES OF SLA [5]}

Second Language Acquisition/SLA is an important branch of applied linguistics, which mainly studies the process and results of people's learning of Second Language. Second language acquisition abbreviates to SLA, which generally refers to the learning of any other language after the acquisition of the mother tongue. SLA was studied mainly from the social, psychological, linguistic and other perspectives. The "second language acquisition" theory describes the learners' features such as their development, changes, their common features and individual differences when learning a second language, and analyzes the internal and external factors influencing second language acquisition. As an independent discipline, the study of second language acquisition was formed in the late 1960s and early 1970s, with a history of more than 30 years. So far, western scholars have proposed many different theories and models in the study of second language acquisition, among which the main ones are habit formation theory, language universality theory, cultural identity theory, social adaptation theory, discourse communication theory, self-monitoring theory, capacity variation theory, cognitive theory and neural function theory. The following is a brief introduction to these theories:

\section{A. The Habit-formation Theory}

Habit-forming theory originated from behaviorism psychology, which was popular in 1950s and 1960s and represented by American behaviorism psychologist Skinner. Behavioristic psychology holds that language is a set of habits, and habits are formed by identifying and reinforcing 
the connection between stimulus and response. Learning a second language is about acquiring a new set of language habits. In this process, imitation and practice play important roles. Imitation can help students identify the connection between verbal stimulus and verbal response, while practice can strengthen the connection between them and form new language habits. Since the process of acquiring a second language is regarded as the process of forming new language habits, the existing language habits -- students' native language -- will inevitably have positive or negative effects on the formation of new language habits. When the first language and the second language have the same language habit, the first language will have a positive impact on the second language acquisition. When two languages have different language habits, the first language will interfere with the second language acquisition, resulting in errors.

\section{B. The Universal Hypothesis}

The theory of linguistic universals stems from the study of linguistic universals in linguistics. There is a consensus on the commonality of natural language, but the research methods are different. There are two typical research methods: one is to reveal the common features of a language through in-depth and detailed study of a language. The representative figure of this method is American linguist Chomsky. The second is to discover the universality of language by comparing and analyzing different languages in different language families. American linguist Greenberg is a representative of studying the universality of language with this method.

\section{The Acculturation Theory}

The theory of cultural identity came into being in the late 1970s. Cultural identity theorists believe that second language acquisition is one aspect of cultural identity. Students' recognition of the culture they have learned determines their mastery of the second language, while cultural identity is determined by the social distance and psychological distance between students themselves and the target language and culture. Social distance is primary, which determines the learning environment. Psychological distance is the second nature. It only works when the current influence on cultural identity is not obvious.

\section{The "Accommodation Theory"}

The theory of social adaptation originated from Giles et al.'s research on group language application in multilingual communities in the late 1970s and early 1980s. The theory of social adaptation is similar to the theory of cultural identity, both of which start from the relationship between students' own social group and the social group of the target language to study the second language acquisition. What is different is that the cultural identity theory thinks that social distance is the actual distance caused by social factors, while the social adaptation theory thinks that social distance is the conscious distance, which was perceived by two groups. According to the theory of social adaptation, in the process of second language acquisition, it is particularly important for students' own social groups to view and define the relationship between the two groups. Cultural identity theory regards social distance and psychological distance as determinants of the success of communication between two groups. Social adaptation theory, on the other hand, holds that the relationship between two groups will be constantly coordinated and adjusted in the process of communication, which is dynamic and it will fluctuate with the change of group concept.

\section{E. The Discourse Theory}

Discourse communication theory originated from Halliday's first language acquisition theory, which was proposed by Hatch in the late 1970s. Halliday believes that communication is the source of language knowledge, and the process of acquiring the first language is actually the process of learning to communicate with language. Hatch agreed with Halliday's point of view. In his opinion, the process of acquiring a second language is not much different from the process of acquiring a first language. Only through discourse communication can students acquire a second language.

\section{F. The Monitor Theory}

Self-monitoring is a second language acquisition theory proposed by American scholar Krashen in the late 1970s.

\section{G. The Variable Competence Theory}

Competence variation theory is second language acquisition theory proposed by English scholar Ellis in the mid-1980s, aiming at explaining the variation of inter language and the internal and external processes of second language acquisition. This theory starts with the analysis of language materials and language use, and tries to explain the second language acquisition in the framework of language use, because the theory believes that the way language acquired reflects the way language used.

\section{H. The Cognitive Theory}

The cognitive theory in the second language acquisition theory developed from the cognitive psychology theory in the early 1980s. In the cognitivist view, learning is a cognitive process that involves adjusting and guiding behavior through mental representation. Learning a second language is actually learning a certain skill. Its psychological expression is based on the language system, including selecting appropriate vocabulary, grammar rules and pragmatic habits. Language behavior improves with the adjustment of psychological performance. As the acquisition of language skills is a very complex task, it involves the practice and coordination of various skills to achieve the degree of ease of use. Therefore, ease of use and readjustment are the two most important concepts in cognitive theory.

\section{The Neurofunctional Theory}

Neuro-functional theory is a second language acquisition theory based on the research results of neurolinguistics. It originated in the late $1970 \mathrm{~s}$ and is represented by the American scholar Mendra. He divided language acquisition into primary language acquisition and secondary language acquisition. These two forms of language acquisition are governed by different neural function systems, each of which have a functional hierarchy system and have different roles in the process of information processing. Language communication and use are mainly controlled by two nervous 
function systems: communication level and cognitive level.

Among the above nine language acquisition theories, "habit formation theory", "cultural identity theory" and "social adaptation theory" are the theoretical basis of this paper.

\section{Cultural DifFERENCES AFFECt SeCOND LANGUAGE ACQUISITION}

The difference between cultures and the influence of culture on language determine that culture have to be involved in the learning of a second language. Language and culture interact with each other, and acquisition of second language is based on the understanding of culture. Due to the differences in culture and language, it is not easy to understand and communicate between different cultures [6]. Communication is a two-way process. In order to facilitate the cross-cultural communication, one should enter into the cultural background of the other, thus involving the issue of cultural background. In intercultural communication many pragmatic failures are caused by different cultural backgrounds [7]. Here, take Korean students' Chinese language acquisition as an example. China and South Korea have a profound cultural origin. In the Goryeo Dynasty and Joseon Dynasty, South Korean national classics were written in Chinese, and ancient Chinese culture had an impact on Korean political system, cultural thoughts and literary creation. Chinese and Korean people live in the same nature and basically have the same understanding of the objective world. However, due to the different environment and historical development of the Chinese and Korean nationalities, their cultures are different from each other. The differences can be divided into six aspects: lexical cultural differences; Cultural differences in language communication; Cultural differences in nonverbal communication; Cultural differences in thinking; Cultural and psychological differences; Differences in cultural backgrounds which mainly means the negative transfer of the mother tongue.

\section{A. Lexical Cultural Differences}

Vocabulary is the cornerstone of language and the most obvious tool to carry cultural information and reflect the cultural life of human society. In languages, in addition to the core part of vocabulary, many words have very specific cultural information, known as the cultural connotation of the word (culturally - loaded words). Each word has a certain cultural background. In the process of second language acquisition mastering the vocabulary differences of two cultures, knowing the different expressions in both languages and understanding their connotation can be helpful in eliminating the interference of oneself culture and constantly correcting the mistakes and errors in vocabulary understanding and application [8].

Korean vocabulary can be divided into three categories from its origin: the inherent word, the Chinese word, the foreign word. Inherent words refer to words originating from Korean language, which accounts for about $20 \%$ of the total vocabulary. Chinese words are made up of Chinese characters, accounting for about 70 percent. There exists a dual system of the inherent word and the Chinese word in
Korean vocabulary. Loanwords refer to words from other languages such as English which account for about $10 \%$ of the total vocabulary. Korean is a kind of agglutinative language featured by depending on the change of ending to express its grammatical relations, which is very different from Chinese. The following is a specific analysis of Korean students' acceptance of Chinese words:

In Chinese there are such words, 穷光蛋 (poor man), 笨蛋 (stupid man), 坏蛋 (bad man), which share a same root “蛋”. And their antonyms are: 富人 (rich man), 聪明人 (smart man), 好人 (good man), which share a same root “人”. Though both of two roots mean "man", they need different words in Chinese. However, some Koreans do not know this rule when they learn Chinese, so they use the Chinese root generation method to become: 富光蛋, 聪明蛋,好蛋. These words are wrong and amused. If Korean students use these words to communicate, they will not express themselves correctly.

In Korean there are a large number of words composed by ancient Chinese characters such as 拜会、祝祭、倦㤐、卒 业生、豫想、宿题、出礼如刑、出将入相、受讲申请、 受纳、受诺、受容、受验、谷食、省墓、党日、后孙、 祈愿、进路、该当、龟鑑、适切、舍廊、便安; till nowadays some words still share the similar meaning with Chinese. Even some Korean poets have the same cultural meaning as Chinese words. Because of this historical and cultural background, Korean students have a strong ability of understanding Chinese vocabulary.

\section{B. Cultural Differences in Language Communication}

Culture is social and shared by social members. The fundamental purpose of second language acquisition is to carry out intercultural communication with people from societies with different cultural backgrounds and speaking different languages. For example, greeting, talking about the weather, and asking about health, age, income and personal privacy, etc., these communication have different social meanings in different countries.

Korea is deeply influenced by Confucianism, and its cultural background is similar to that of China. But it is much stricter than China in terms of title. In South Korea, friends who are bigger than themselves are not allowed to call each other by their first names. The specific usage of "brother" and "sister" in Korean is a little different from that in Chinese. In Korean, the gender of the speaker is different, and the names of "brother" and "sister" are also different: the younger brother calls the elder brother [hi nim]; the younger sister calls the elder brother [op'a]; the younger brother calls the elder sister [nuna]; and the younger sister calls the elder sister [nni].Just as in China, the speaker's address to his younger brother and sister is not restricted by his gender. It shows respect of Korean for older people. Interestingly, older men refer to women younger than him as [nni], which is a nickname in Korean and $i$ is used to call waiters in restaurants. In South Korea, in recent years, young women, especially female college students, have referred to upper classman as 
[hi nim].In addition, both male and female students have some unique expressions, which reflect the variation of a language. Student language is in some ways a variant on the society, while female language is a variation among the variants. "Older brother", in addition to call the older male friends, has a special meaning in certain situations, that is, girls also call their boyfriends "older brothers" before they get married. After marriage, the husband is generally no longer called "older brother". If a girl calls a boy "older brother", there are three possible situations: (1) biological brother; (2) male friends or seniors; (3) her boyfriend. Chinese people usually cannot recognize their relationship from their appellation. But South Koreans can hear it. South Koreans do not feel shy when they are addressed in this way. Instead, they feel polite and friendly. In China, the title elder sister and brother usually are used to call relatives except some rural areas in China. Therefore, Chinese students are unaccustomed to appellations which are used by Korean students.

\section{Cultural Differences in Nonverbal Communication}

The tools of human communication include language, but language definitely is not the only one. Language communication mainly conveys the content of thought, while non-language communication shows the way of communication and embodies the essence of the relationship between the two sides. Successful communication includes not only the language aspect, but also the non-language aspect [9]. Choosing which action depends on sex and intimacy. Handshake, arm in arm or holding shoulder is the most intimate expression of a greeting or farewell. The physical touch of the Chinese is far less obvious than that of the Koreans, because Chinese usually hide their rich feelings. Sino-South Korean young people also have different places on the emotional expression. Especially in recent years, due to the profound influence by western culture, the way young people showing their emotion is more and more opening. High school students fall in love at the age of 14 or 15 are common phenomena now. Exchanges between men and women are less taboo. Clapping a girl's hair intimately, leaning on shoulders and hands in hands, all these behaviors are universal between a man and woman even in common relationship. But in Chinese campuses, these actions usually occur only between lovers. If Korean students cannot distinguish these culture dereference, they will be misunderstood when they contact with Chinese male or female.

From the perspective of rhetoric, language application in different occasions is different. The language used to speak to elders and friends must be different. Choose formal language or informal language according to different contexts. Taking Korean as an example, Korean has the honorific language and non-honorific language. The junior should use honorific language when he/she talks with the elder or superiors; the elder should use non-honorific language to the junior and peers also use non-honorific language. That is the reason why they form the habit of asking the age when they meet each other for the first time, which is different for Chinese.

\section{Culture Differences in Thinking}

Different cultures of different nations have different ways of thinking. They must give consideration to both language and culture, realizing the importance of culture and language, and understand cultural differences. Korean has strict grammar rules. In contrast, Chinese sentence structure is relatively loose and flexible, because we focus on meaning rather than shape and conjunction. It's not hard to learn to speak Korean, but it's not easy to write a passage in Korean because of the strict grammar. Some Chinese sentences are ambiguous and should be distinguished according to the context. Relatively speaking, Korean sentences are less ambiguous.

South Korea is adjacent to China, which has historical ties with Confucianism as the mainstream culture. In some terms, the word-formation thinking is basically the same. When the lovers broke up, both Chinese and Korean would express "kicked". Describing A looks down on B Korean will say "A has a high nose" and Chinese will say "A has a high eye". When describing one has no shame, Chinese will say that: "his face is as thick as a city wall", and Korean will say that "his face is as thick as land". From the above we can see in Chinese and Korean the idea of word formation is the same. Therefore, the Korean people receive quickly when learning Chinese, which has a lot to do with their language and cultural background.

\section{E. Cultural and Psychological Differences}

Many Chinese words carry unique cultural imprint, and even the simplest words are no exception, so it is difficult to find a complete equivalent Korean to explain. For example, the word "friend" belongs to a kind of relationship in the "Five Relations" of Confucian civilization. When translated into Korean, the students assumed the names of their peers. Not the friend mentioned in The Analects. Public opinion in ancient China valued friends more than wives. Even now it still means tight relationship. The word "friend" can be extended other meanings by change the attachment relating words such as 损友 (bad friends), 益友 (good friends), 訽颈 之交(friends you can trust with your life), 忘年交(friendship between the young and the old), etc. These words are blank in Korean.

The special love of Chinese people is "fighting" and "fearing", that is flirting, and uxoriousness. Students from South Korea were surprised by this particular approach, because in their country people have a conservative view of women. Gender differences are still prevalent in daily life and consciousness. For example, “红杏出墙” (meaning female is disloyal to her husband) we can only use it to describe women. But when to say that men's philandering is " 寻花问柳" (which is a little commendatory). This is also related to the traditional Chinese culture of gender differences, which is easier for Korean students to understand.

\section{F. $\quad$ Differences in cultural background affected by} negative transfer of mother tongue

The position of Chinese preposition is different from that 
of Korean adverb case auxiliary. In Chinese, when the preposition "in" is combined with a noun or nominal phrase to form a preposition phrase, the preposition is in the front and the postposition is in the rear, and the format is: "preposition + nominal". However, in Korean, when the adverb of the place is combined with the nominal, the adverb is in the rear, and the format is: "nominal + adverb case auxiliary". Therefore, when Korean students translate Korean into Chinese, the first thing that comes to mind is a notional word, and then they will consider whether to use a preposition. Due to the differences between the two languages, in many cases, the ending or auxiliary words in Korean cannot correspond to any function words when converted into Chinese, because Chinese can express the corresponding grammatical meaning by word order or other grammatical ways. Similarly, when Korean adverbs are translated into Chinese, they can correspond to the corresponding prepositions or not. Using the adverb or not is determined by the syntactic structure and semantic requirements of Chinese sentences [10]. (Zhou Chunjie 2005) Therefore, according to the way of thinking of Korean students, they will consider whether to use the corresponding preposition after choosing the notional word for place.

\section{E.g.:}

1). Neither my mother nor I have ever been on a train in China. This is our first travel (in) China.

2). I went out of town for the first time after high school and lived (in) Seoul for a year.

Where there is (), there should be a preposition. But South Korean students influenced by their mother tongue so they usually forgot to use it. In addition, in terms of grammar, Chinese is SVO word order and Korean is SOV word order. That is to say, in Chinese object is in front verb, but Korean is on the contrary. Chinese presents semantic and functional changes through changes in word order, while Korean presents these changes through post morphological changes. So "I ate lunch" in Chinese but "I lunch ate" in Korean. "I like Korean food" in Chinese but "I Korean food like" in Korean. Therefore, when Korean students acquire Chinese, they can compare the grammar of the two languages, knowing the differences and mastering Chinese well. From the perspective of language acquisition theory, it is the "theory of linguistic universals"

\section{CONCLUSION}

The education of language in any nation has a tendency of cultural migration. Because no nation will be inferior to its own culture, but will be more or less proud of it, thus consciously or unconsciously generating cultural migration initiative [6]. (Dai Qingxia 1994) Especially in a nation with a long history and various traditions, when its culture is respected by outsiders, it will transfer automatically. In addition, those who learn the target language will consciously accept the culture of the target language and realize more function of the language from the culture. This kind of cultural transfer and active acceptance can be fully reflected in the second language acquisition process. From the perspective of language learning, it is difficult to learn the language without understanding the customs, etiquette, thinking habits and values of the target language countries and without skipping over the obstacles caused by social and cultural differences. Language, especially Chinese itself, is closely related to national cultural and psychological structure. Strictly speaking, Chinese lacks the morphological changes and it has the "unique non-morphological humanism". Chinese is largely a formless language with strong humanism. Context and cultural atmosphere have a great influence on the meaning of words, sentences and paragraphs. Age, gender, occupation, race, region, education level, social class and individual speech characteristics are all the social and cultural implications of language. The pragmatic failures of Korean students in learning Chinese are mostly caused by cultural factors (as analyzed above). Culture is basically a process of accumulation. Its original social experience, life experience, cultural knowledge and thinking ability will become a booster for learners to know and understand the culture of the country where the target language is spoken. Therefore, cultural differences have a direct impact on second language acquisition.

\section{REFERENCES}

[1] Y. Sun, Introduction to Bible, Beijing: People's University of China Press, 2005.

[2] J. F. Ma, "A preliminary study on the modeling of Chinese teaching," Language Teaching and Research, no. 1, 2004.

[3] B. Y. Chen, Linguistic and Cultural Theory, Kunming: Yunnan University Press, 1993.

[4] W. Z. Sun, "Cultural flow and the diffusion of language," Journal of Social Sciences, no. 1, 1989.

[5] L. Lin, Second Language Acquisition: Theory and Practice, Beijing: Higher Education Press, 2007.

[6] Q. X. Dai, Language and Nation, Beijing: Central University for Nationalities Press, 1994.

[7] J. M. Lu, "Strengthening discipline awareness and developing teaching Chinese as a foreign language," Chinese Teaching in the World, no. 1, 2004.

[8] T. Lin, "Phonetics research and teaching chinese as a foreign language world Chinese teaching," Chinese Teaching in the World, no. 3, 1996.

[9] J. M. Zhao, "Some principles of teaching Chinese grammar to foreigners," Language Teaching and Research, no. 3, 1994.

[10] C. J. Zhou, "Error analysis of the preposition 'in' using by Korean students," Chinese Teaching and Research, Seoul Press, 2005, p. 209.

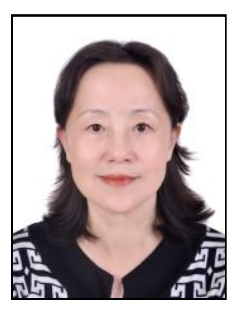

Yaping Tang was born in 1960 in Kunming Yunnan, she is a professor of Yunnan Nationalities University. Tang obtained the bachelor's degree in Chinese language and literature, she is with the mainly research field in linguistics and Chinese international education.

She is mainly engaged in the research and teaching of linguistics and Chinese international education. She published more than 30 independently completed published dictionaries and textbooks. 